\title{
Estimation of sinking velocity using free-falling dynamically scaled models: Foraminifera as a test case
}

\author{
Matthew Walker ${ }^{1, \pm}$, Jörg U. Hammel ${ }^{2}$, Fabian Wilde ${ }^{2}$, Tatjana Hoehfurtner ${ }^{1}$, Stuart Humphries ${ }^{1}$ and \\ Rudi Schuech ${ }^{1, *}$
}

\begin{abstract}
The velocity of settling particles is an important determinant of distribution in extinct and extant species with passive dispersal mechanisms, such as plants, corals and phytoplankton. Here, we adapted dynamic scaling, borrowed from engineering, to determine settling velocity. Dynamic scaling leverages physical models with relevant dimensionless numbers matched to achieve similar dynamics to the original object. Previous studies have used flumes, wind tunnels or towed models to examine fluid flow around objects with known velocities. Our novel application uses free-falling models to determine the unknown sinking velocity of planktonic Foraminifera - organisms important to our understanding of the Earth's current and historic climate. Using enlarged 3D printed models of microscopic Foraminifera tests, sunk in viscous mineral oil to match their Reynolds numbers and drag coefficients, we predicted sinking velocity of real tests in seawater. This method can be applied to study other settling particles such as plankton, spores or seeds.
\end{abstract}

KEY WORDS: Hydrodynamics, Settling, Dynamic scaling, Model, Drag

\section{INTRODUCTION}

The transport of organisms and biologically derived particles through fluid environments strongly influences their spatiotemporal distribution and ecology. In up to a third of terrestrial plants (Willson et al., 1990), reproduction is achieved through passive movement of propagules (e.g. seeds) on the wind. In aquatic environments, propagules of many sessile groups from corals (Jones et al., 2015) to bivalves (Booth, 1983) are dispersed by ambient currents, eventually settling out of the water column to their final locations. Furthermore, most dead aquatic organisms (from diatoms to whales) sink, transporting nutrients to deeper water and contributing to long-term storage of carbon (De La Rocha and Passow, 2007). In the case of microfossils, the sinking dynamics of the original organisms even influences our reconstructions of the

\footnotetext{
${ }^{1}$ School of Life Sciences, Joseph Banks Laboratories, University of Lincoln, Green Lane, Lincoln LN6 7DL, UK. ${ }^{2}$ Institute of Materials Research, Helmholtz-Zentrum Geesthacht, Outstation at DESY, Building 66, Notkestr. 85, D-22607 Hamburg, Germany.

*Present address: Center for Computational Science, Stanley Thomas Hall 405 Tulane University, 6823 St Charles Ave, New Orleans, LA 70118, USA.

‡Author for correspondence (matthewwalkerbio@gmail.com)
}

(D) M.W., 0000-0002-9865-1375; J.U.H., 0000-0002-6744-6811; F.W., 0000-00026080-3601; T.H., 0000-0003-0518-5481; S.H., 0000-0001-9766-6404; R.S., 00000002-3533-0582

This is an Open Access article distributed under the terms of the Creative Commons Attribution License (https://creativecommons.org/licenses/by/4.0), which permits unrestricted use, distribution and reproduction in any medium provided that the original work is properly attributed.

Received 18 June 2020; Accepted 10 December 2020
Earth's paleoclimate (Van Sebille et al., 2015). Crucially, the horizontal distances over which all these biological entities are transported, and therefore their distribution, are affected by their settling velocity (Ali et al., 2011).

Measuring the individual settling velocity of small particles directly is challenging, especially when they are too small to be imaged easily without magnification (e.g. Walsby and Holland, 2006). Here, we applied dynamic scaling, an approach commonly used in engineering, to circumvent this difficulty and accurately quantify the kinematics of sub-millimetre-scale free-falling particles using enlarged physical models. We used scaled-up physical models in a high-viscosity fluid, enabling easy measurement of settling speed, orientation and other parameters using inexpensive standard high-definition web cameras. While dynamically scaled models have previously been employed to study a number of problems in biological fluid mechanics (e.g. Vogel et al., 1973; Vogel, 1987, 1994; Koehl, 2003), the study of freely falling particles of complex shape - for which settling speed is the key unknown parameter - presents a unique challenge to experimental design that we overcome in this work.

Engineering problems such as aircraft and submarine design often are approached using scaled-down models in wind tunnels or flumes to examine fluid flows around the model and the resulting fluid dynamic forces it is subjected to. To ensure that the behaviour of the model system is an accurate representation of real life, similarity of relevant physical phenomena must be maintained between the two. If certain dimensionless numbers (i.e. ratios of physical quantities such that all dimensional units cancel) that describe the system are equal between the life-size original and the scaled-down model, 'similitude' is achieved and all parameters of interest (e.g. velocities and forces) will be proportional between prototype and model (Zohuri, 2015). Intuitively, the model and real object must be geometrically similar (i.e. have the same shape), so that the dimensionless ratio of any length between model and original, Length ${ }_{\text {model }} /$ Length $_{\text {real }}$, is constant - this is the scale factor $(S)$ of the model. Less obvious is the additional requirement of dynamic similarity, signifying that the ratios of all relevant forces are constant. For completely immersed objects sinking steadily at terminal velocity (achieved quickly for most small particles, see Materials and Methods, 'Time to terminal velocity'), dynamic similarity is achieved by matching the Reynolds number $(R e)$.

$R e$ is a measure of the ratio of inertial to viscous forces in the flow (Batchelor, 2000; within a biological context: Vogel, 1994), and is typically defined as:

$$
R e=\frac{L U \rho_{\text {fluid }}}{\mu},
$$

where $\rho_{\text {fluid }}$ is the density of the fluid $\left(\mathrm{kg} \mathrm{m}^{-3}\right) ; L$ is a characteristic length $(\mathrm{m})$ of the object; $U$ is the object's velocity $\left(\mathrm{m} \mathrm{s}^{-1}\right)$; and $\mu$ is 


\begin{tabular}{ll} 
List of symbols and abbreviations \\
$A$ & particle projected (frontal) area perpendicular to flow \\
$A r$ & Archimedes number \\
$C_{\mathrm{D}}$ & coefficient of drag \\
$C_{\mathrm{D}}^{\mathrm{E}}$ & interpolating spline through $\left(R e, C_{\mathrm{D}}\right)$ experimental data \\
$C_{\mathrm{D}}^{\mathcal{F}}$ & $C_{\mathrm{D}}$ determined through a force balance \\
$C_{\mathrm{D}}^{\infty}$ & $C_{\mathrm{D}}$ in an unbounded domain (i.e. in the ocean) \\
$C_{\mathrm{D}}^{\text {walls }}$ & $C_{\mathrm{D}}$ with walls present (i.e. measured in the tank) \\
$F_{\text {buoyancy }}$ & buoyant force \\
$F_{\mathrm{drag}}$ & drag force \\
$F_{\text {weight }}$ & particle weight \\
$\boldsymbol{g}$ & acceleration due to gravity \\
$H$ & cubic spline interpolant for measured $V$ versus $S$ \\
$K$ & wall effects correction factor \\
$L$ & maximum length of particle parallel to the flow \\
$M$ & particle mass \\
$N$ & iteration number \\
$\mathrm{O}$ & value for real particle at natural operating point \\
$R e$ & Reynolds number \\
$S$ & model scale factor \\
$U$ & sinking speed of particle \\
$V$ & particle volume \\
$Z(t)$ & depth of the sphere \\
$\lambda$ & tank to particle diameter ratio \\
$\mu$ & fluid viscosity \\
$\rho_{\text {fluid }}$ & fluid density \\
$\rho_{\text {particle }}$ & particle density \\
$\Sigma F$ & sum of external forces \\
$\Psi$ & 3D shape \\
& \\
\hline &
\end{tabular}

the dynamic viscosity ( $\mathrm{N} \mathrm{s} \mathrm{m}^{-2}$, or Pa s) of the fluid. In cases where $L U \rho_{\text {fluid }}$ is large compared with $\mu$, e.g. whales, birds and fish (Re $\approx 3 \times 10^{9}$ to $3 \times 10^{6}$; Vogel, 1994), inertial forces dominate. In cases where $L U \rho_{\text {fluid }}$ is relatively small compared with $\mu$, e.g. sperm, bacteria $\left(R e \approx 3 \times 10^{-2}\right.$ to $\left.1 \times 10^{-5}\right)$, viscous forces dominate. Finally, when $L U \rho_{\text {fluid }}$ is of comparable magnitude to $\mu, R e$ is intermediate and one cannot discount either inertial or viscous forces. If the scaled model and original system exhibit identical $R e$, the relative importance of inertial versus viscous forces is matched between the two and any qualitative features of the flows (e.g. streamlines) will also be identical.

Dynamically scaled physical models exhibiting the same Re as the original systems have been used in a number of biological studies. Vogel and La Barbera (1978) outline the principles of dynamic scaling: to obtain the same $R e$ when enlarging small organisms, the fluid flow must be slower and/or the fluid more viscous, and when making smaller models of large organisms, the fluid flow must be faster and/or the fluid less viscous. For instance, Vogel (1987) used air in place of water flowing at lower speeds when investigating the refilling of the squid mantle during swimming by scaling up a model 1.5 times relative to the animal's actual size. More recently, Stadler et al. (2016) investigated sand inhalation in skinks with 3D-printed enlarged models, using helium instead of air (thereby increasing viscosity) as the experimental fluid. Koehl and colleagues have studied crustacean antennule flicking (lobsters: Reidenbach et al., 2008; mantis shrimp: Stacey et al., 2002; and crabs: Waldrop et al., 2015) as well as the movements of copepod appendages (Koehl, 1995) with enlarged models, using mineral oil in place of water. Finally, perhaps the largest change in scale was employed by Kim et al. (2003), who modelled the bundling of $E$. coli flagella at a scale factor of $\sim 61,000$, submerged in silicone oil $\left(10^{5}\right.$ times more viscous than water), and rotated at $0.002 \mathrm{rpm}$ compared with the $600 \mathrm{rpm}$ observed in real bacteria (Sowa and Berry, 2008).

In all the above studies, basic kinematics such as speed in the original system were relatively easy to measure, and the experiments aimed to reveal the forces involved (e.g. hydrodynamic drag) or details of the fluid flow such as the pattern of streamlines. As the representative speed $(U)$ of the original system was known, designing experiments to achieve similitude was relatively straightforward because the Re was also known a priori - in these cases, the model size, speed and working fluid properties were simply interrelated through $\operatorname{Re}$ (Eqn 1). For instance, once a working fluid and the model size were chosen, the required towing speed was obvious. However, in the case of sedimentation of small particles (e.g. spores, seeds, plankton), the sinking speed $(U)$ is the key unknown. With an unknown sinking speed, the operating $R e$ is also unknown, so it is not straightforward to design experiments that achieve similitude with the original system. Here, we present an iterative methodology leveraging 3D printed dynamically scaled models that allows determination of the sinking speed of small objects of arbitrarily complex shape.

We used planktonic organisms of the subphylum Foraminifera (hereafter referred to as the group 'foraminifera') as an example of a small $(200-1500 \mu \mathrm{m})$ biological particle for which the settling velocity is important and typically unknown. Foraminifera are marine amoeboid protists (Gupta, 2002; Schiebel and Hemleben, 2005). By secreting calcium carbonate, foraminifera produce a multi-chambered shell (test) which, in planktonic foraminifera, can grow up to $1500 \mu \mathrm{m}$ in diameter, and which frequently exhibits a complex shape (Table 1). Once the organism dies or undergoes reproduction, the empty test sinks to the ocean floor, and so oceanic sediment contains substantial numbers of foraminifera tests. Foraminifera account for $23-56 \%$ of the oceans' production of carbonate $\left(\mathrm{CO}_{3}\right)$ (Schiebel, 2002), an important factor in climate change models (Passow and Carlson, 2012). Of particular interest for climate predictions is calculating the flux of tests reaching the ocean floor (Schiebel, 2002; Jonkers and Kučera, 2015). While there are more than 30 extant species and over 600 species in the fossil record, settling velocities are known for only 14 species of foraminifera (Fok-Pun and Komar, 1983; Takahashi and Be, 1984; Caromel et al., 2014: $3.41 \times 10^{-4}$ to $6.8 \times 10^{-2} \mathrm{~m} \mathrm{~s}^{-1}$, $\operatorname{Re} \approx 18-55$ ).

\section{MATERIALS AND METHODS}

\section{Similitude and settling theory}

We assume that the size (i.e. $L$ - defined as the maximum length parallel to the settling direction, $A$ - defined as the projected frontal area, and $V$ - the particle volume not including any fluid-filled cavities), 3D shape ( $\psi$, here treated as a categorical variable because of our consideration of arbitrarily complex morphologies; see Table 1$)$ and density $\left(\rho_{\text {particle }}\right)$ of the original sinking particle are known, while the sinking speed $(U)$ is unknown. The properties of the fluid surrounding the original particle (i.e. $\rho_{\text {fluid }}, \mu$ ) are also known, and our goal is to design experiments in which we sink a scaled-up model particle in a working fluid of known $\rho_{\text {fluid }}$ and $\mu$ in order to determine the model particle's sedimentation speed and, via similitude, $U$ of the original particle.

While previous work (Berger and Piper, 1972; Fok-Pun and Komar, 1983; Takahashi and Be, 1984; Caromel et al., 2014) suggests that the Re of sinking foraminifera should be $10^{\circ}-10^{2}$, the exact value of $R e$ for morphology $\psi$ is assumed to be unknown. 
Table 1. Predicted sinking speeds $U^{0}$ for the 30 species of planktonic foraminifera included in this study

\begin{tabular}{|c|c|c|c|c|c|c|c|}
\hline Image & Species & $L^{\circ}(\mu \mathrm{m})$ & $U^{\circ}\left(\mathrm{cm} \mathrm{s}^{-1}\right)$ & $R e^{O}$ & $C_{D}^{\circ}$ & $C_{D}^{\mathrm{M}}\left(R e^{\mathrm{O}}\right)$ & Iterations \\
\hline & Neogloboquadrina acostaensis (Blow 1959) & 307 & 3.6 & 9.3 & 2.5 & 4.2 & 4 \\
\hline & Globigerinella adamsi (Banner and Blow 1959) & 596 & 3.0 & 9.6 & 2.6 & 4.1 & 4 \\
\hline & Dentoglobigerina altispira (Cushman and Jarvis 1936) & 282 & 6.1 & 37.3 & 1.6 & 1.8 & 5 \\
\hline & Globoturborotalita apertura (Cushman 1918) & 650 & 2.8 & 7.4 & 4.2 & 4.8 & 3 \\
\hline & Globigerina bulloides d'Orbigny 1826 & 296 & 3.3 & 13.4 & 2.4 & 3.3 & 5 \\
\hline & Globigerinoides conglobatus* (Brady 1879) & 445 & 1.8 & 5.8 & 5.9 & 5.7 & 4 \\
\hline & $\begin{array}{l}\text { Globorotalia (Truncorotalia) crassaformis (Galloway and Wissler } \\
\text { 1927) }\end{array}$ & 250 & 3.3 & 9.5 & 2.3 & 4.1 & 4 \\
\hline & Neogloboquadrina humerosa (Takayanagi and Saito 1962) & 360 & 5.0 & 22.7 & 2.0 & 2.4 & 4 \\
\hline & Globoconella inflata (d'Orbigny 1839) & 422 & 3.9 & 21.4 & 2.5 & 2.5 & 4 \\
\hline & Fohsella lobata (Bermúdez 1949) & 312 & 4.2 & 13.1 & 1.5 & 3.3 & 3 \\
\hline & Globorotalia margaritae Bolli and Bermúdez 1965 & 258 & 2.9 & 8.1 & 2.8 & 4.6 & 3 \\
\hline & Paragloborotalia mayeri (Cushman and Ellisor 1939) & 298 & 3.1 & 8.1 & 3.2 & 4.5 & 4 \\
\hline & Globoturborotalita nepenthes (Todd 1957) & 353 & 4.2 & 16.4 & 2.4 & 2.9 & 3 \\
\hline & Pulleniatina obliquiloculata (Parker and Jones 1865) & 350 & 4.1 & 24.6 & 2.1 & 2.3 & 3 \\
\hline & Fohsella peripheroronda (Blow and Banner 1966) & 422 & 3.6 & 10.1 & 2.4 & 4.0 & 3 \\
\hline & Praeorbulina curva (Blow 1956) & 433 & 4.8 & 17.8 & 2.2 & 2.8 & 3 \\
\hline & Sphaeroidinella dehiscens (Parker and Jones 1865) & 460 & 5.1 & 32.8 & 1.7 & 1.9 & 4 \\
\hline & Sphaeroidinella dehiscens* (Parker and Jones 1865) & 269 & 2.5 & 8.3 & 5.0 & 4.5 & 4 \\
\hline & Catapsydrax dissimilis (Cushman and Bermúdez 1937) & 380 & 6.2 & 36.4 & 1.7 & 1.8 & 4 \\
\hline & Neogloboquadrina dutertrei (d'Orbigny, 1839) & 259 & 4.0 & 17.6 & 2.0 & 2.8 & 3 \\
\hline & Globigerinoidesella fistulosa (Schubert 1910) & 392 & 2.6 & 11.2 & 3.0 & 3.7 & 4 \\
\hline
\end{tabular}


Table 1. Continued

\begin{tabular}{|c|c|c|c|c|c|c|c|}
\hline Image & Species & $L^{\circ}(\mu \mathrm{m})$ & $U^{O}\left(\mathrm{~cm} \mathrm{~s}^{-1}\right)$ & $R e^{O}$ & $C_{D}^{\circ}$ & $C_{D}^{\mathrm{M}}\left(R e^{\mathrm{O}}\right)$ & Iterations \\
\hline & Globorotaloides hexagonus (Natland 1938) & 321 & 2.7 & 8.3 & 3.4 & 4.5 & 4 \\
\hline & Globigerinella obesa (Bolli 1957) & 539 & 2.8 & 9.4 & 3.2 & 4.1 & 4 \\
\hline & Globorotalia praemenardii Cushman and Stainforth 1945 & 569 & 3.9 & 14.0 & 2.0 & 3.2 & 4 \\
\hline & Globoconella puncticulata (d'Orbigny in Deshayes 1832) & 269 & 4.0 & 14.5 & 2.8 & 3.1 & 3 \\
\hline & Fohsella robusta (Bolli 1950) & 312 & 3.5 & 11.2 & 2.3 & 3.7 & 4 \\
\hline & Dentoglobigerina tripartita (Koch 1926) & 303 & 5.7 & 33.6 & 2.0 & 1.9 & 3 \\
\hline & Paragloborotalia siakensis (LeRoy 1939) & 366 & 3.4 & 10.4 & 2.6 & 3.9 & 4 \\
\hline & Globoconella sphericomiozea (Walters 1965) & 627 & 4.3 & 18.8 & 2.3 & 2.7 & 4 \\
\hline & Globorotalia (Truncorotalia) truncatulinoides (d'Orbigny 1839) & 325 & 6.3 & 42.4 & 1.5 & 1.6 & 6 \\
\hline & Orbulina universa* d'Orbigny 1839 & 567 & 1.0 & 3.3 & 10.7 & 8.7 & 6 \\
\hline
\end{tabular}

Each species is shown in both spiral view and 90 deg rotation (so that the spiral view is facing to the left). Asterisks indicate species scanned at high resolution. Scans of the remaining 27 species were obtained from The University of Tohoku museum's database. Operating Reynolds number $\left(R e^{\bigcirc}\right)$ and coefficient of drag $\left(C_{D}{ }^{\circ}\right)$ predicted for each species are also presented, and for comparison, the theoretical $C_{D}^{\mathrm{M}}$ of a sphere at the same $R e^{\mathrm{O}}$ predicted by Morrison's equation (indicated by superscript $\mathrm{M}$ ). The number of model iterations required to achieve convergence of $U^{O}$ is listed. Species synonyms were checked in the World Foramaninifera Database (http://www.marinespecies.org/foraminifera/, accessed: 23 September 2020).

Hence, it is not immediately clear what size the model should be (i.e. the scale factor $\left.S=L_{\text {model }} / L_{\text {real }}\right)$ in order to match this $R e$ in the experiments and ensure similitude. Solving for both $R e$ and $S$ simultaneously requires additional mathematical relationships beyond Eqn 1.

Throughout, we use a superscript $\mathrm{O}$ to refer to the original values of dimensioned variables at life size (e.g. $L^{\mathrm{O}}, V^{\mathrm{O}}, A^{\mathrm{O}}$, $\rho_{\text {particle }}^{\mathrm{O}}, U^{\mathrm{O}}$ ) and $R e^{\mathrm{O}}, C_{\mathrm{D}}^{\mathrm{O}}$ for the values of the dimensionless Reynolds number and drag coefficient (defined below) corresponding to real particles sinking in the original fluid (e.g. seawater of $\rho_{\text {fluid }}^{\mathrm{O}}, \mu^{\mathrm{O}}$ ). While the fluid dynamics of flow around a particle of particular shape $\psi$ can be considered theoretically over a range of $R e$, only the dynamics at $R e^{\mathrm{O}}$ and $C_{\mathrm{D}}^{\mathrm{O}}$ will represent the 'operating point' corresponding to the life-size particle settling speed $U^{\mathrm{O}}$.

When a particle is sinking steadily at its terminal velocity, the sum of the external forces $(\Sigma F)$ acting on the particle is zero (Fig. 1A, Eqn 2); that is, the upward drag force ( $F_{\text {drag }}$, Eqn 3$)$ and buoyant force ( $F_{\text {buoyancy }}$, Eqn 4$)$ must balance the weight of the particle $\left(F_{\text {weight }}\right.$, Eqn 5):

$$
\Sigma F=F_{\text {drag }}+F_{\text {buoyancy }}-F_{\text {weight }}=0,
$$

where

$$
F_{\text {drag }}=\frac{1}{2} C_{\mathrm{D}}(\Psi, R e) \rho_{\text {fluid }} U^{2} A .
$$

Eqn 3 introduces the drag coefficient $C_{\mathrm{D}}(\psi, R e)$, a dimensionless descriptor of how streamlined an object is. Both $C_{\mathrm{D}}$ and $R e$ must be matched to achieve similitude. $C_{\mathrm{D}}$ depends on the shape of the object $\psi$, including its orientation relative to the freestream flow; for instance, $C_{\mathrm{D}}$ of a flat plate oriented parallel to laminar flow is as low as 0.003 while $C_{\mathrm{D}}$ of a flat plate oriented perpendicular to the flow is $\sim 2.0$ (Munson et al., 1994). However, in addition to object geometry, $C_{\mathrm{D}}$ also depends on qualitative characteristics of the flow, such as whether it is laminar or turbulent - that is, $C_{\mathrm{D}}$ also depends on $\operatorname{Re} . C_{\mathrm{D}}$ of a sphere decreases from about 200 at $R e=0.1$ to about 0.5 at $R e=1000 ; C_{\mathrm{D}}$ generally decreases with $R e$ for most shapes (Munson et al., 1994; Morrison, 2013). While $C_{\mathrm{D}}$ does not depend on object size directly, larger objects generally experience higher drag forces and this is captured by the inclusion of particle area $(A)$ in the expression for $F_{\text {drag }}$ (Eqn 3). For brevity, we will omit $\psi$ hereafter and write the drag coefficient as $C_{\mathrm{D}}(R e)$.

The buoyant force ( $\left.F_{\text {buoyancy, Eqn }} 4\right)$ and weight ( $F_{\text {weight }}$, Eqn 5 ) are both expressed using particle volume $(V)$, gravitational 


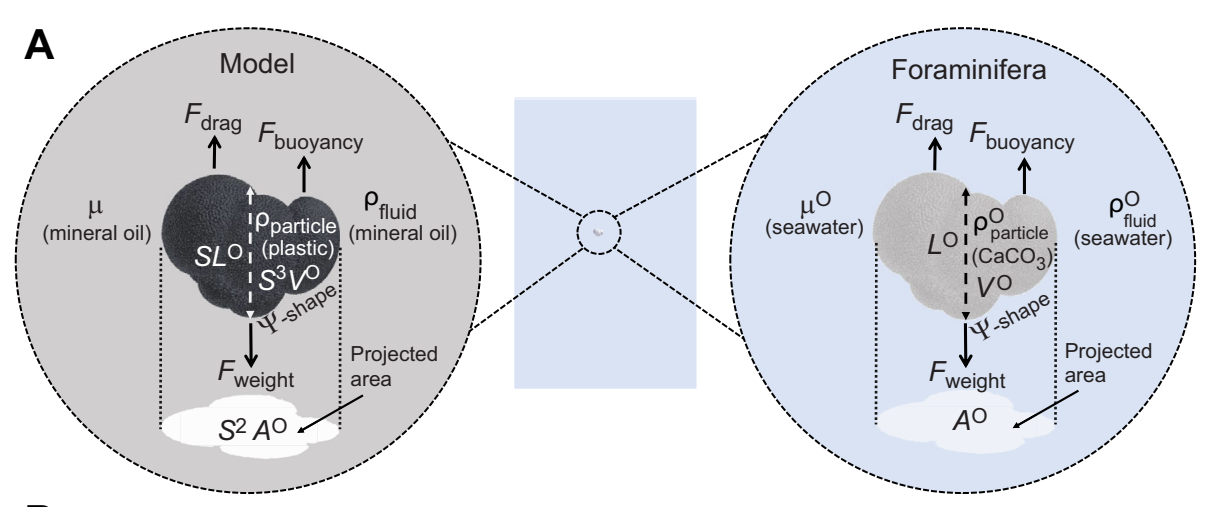

B

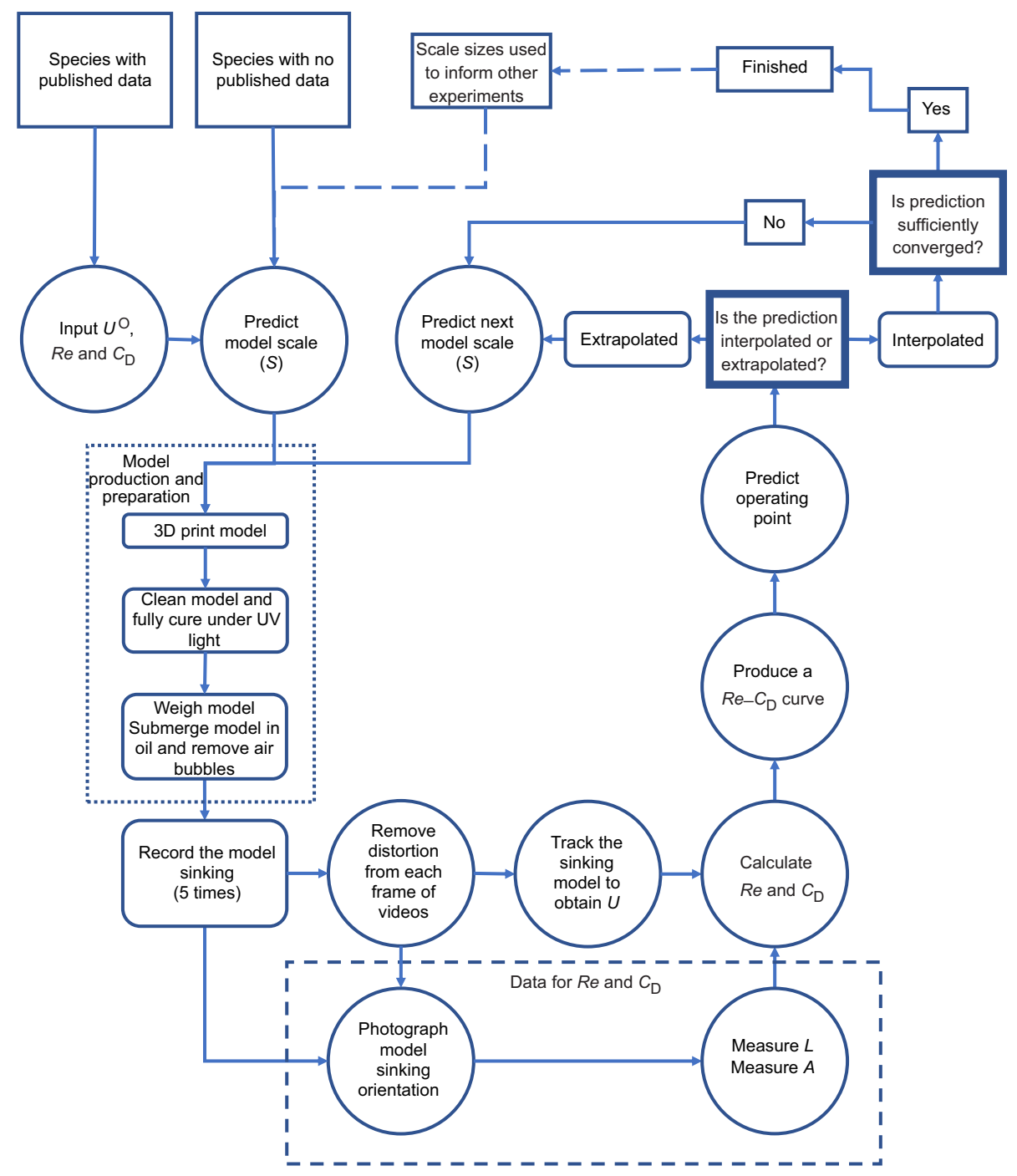

Fig. 1. Model systems and summary of method. (A) Diagram of relevant forces and parameters between the model (left) and real life (right). (B) Summary of the full method; details are discussed in the main text. Boxes with thicker lines represent a decision, square boxes are data inputs, rounded square boxes are manual processes, and circles are computational steps. $A^{\mathrm{O}}$, projected area; $C_{\mathrm{D}}$, drag coefficient; $F_{\text {drag, }}$, drag force; $F_{\text {buoyancy; }}$ buoyancy force; $F_{\text {weight }}$, particle weight; $L$, maximum length of particle; $R e$, Reynolds number; $S$, model scale factor; $U$, sinking speed of particle; $V^{\circ}$, particle volume; $\mu$, fluid viscosity; $\rho_{\text {fluid, }}$ density of experimental fluid; $\rho_{\text {fluid }}$, density of seawater; $\rho_{\text {particle }}$, density of plastic used to make the model; $\rho_{\text {particle, }}^{\mathrm{O}}$ density of particle; $\psi$, particle shape. acceleration $(\boldsymbol{g})$ and density of the fluid ( $\left.\rho_{\text {fluid }}\right)$ or particle $\left(\rho_{\text {particle }}\right)$, respectively:

$$
\begin{aligned}
& F_{\text {buoyancy }}=V \rho_{\text {fluid }} g, \\
& F_{\text {weight }}=V \rho_{\text {particle }} g .
\end{aligned}
$$

Substituting Eqns 3, 4 and 5 into Eqn 2 and eliminating $U$ via the definition of $\operatorname{Re}$ (Eqn 1) yields an expression for the drag coefficient obtained through a force balance (indicated by a superscript $\mathcal{F}$ ):

$$
\begin{aligned}
C_{\mathrm{D}}^{\mathcal{F}}(R e) & =\frac{2\left(\rho_{\text {particle }}-\rho_{\text {fluid }}\right) V \boldsymbol{g}}{\rho_{\text {fluid }} U^{2} A} \\
& =\left(\frac{2\left(\rho_{\text {particle }}-\rho_{\text {fluid }}\right) V \boldsymbol{g}}{\rho_{\text {fluid }} A}\right)\left(\frac{\rho_{\text {fluid }} L}{\operatorname{Re} \mu}\right)^{2} \\
& =\frac{2\left(\rho_{\text {particle }}-\rho_{\text {fluid }}\right) \rho_{\text {fluid }} V \boldsymbol{g} L^{2}}{A R e^{2} \mu^{2}} .
\end{aligned}
$$


Note that this expression can be simplified further upon identification of the dimensionless Archimedes number $A r=g L^{3}{ }_{A l} \rho_{\text {fluid }}$ ( $\left.\rho_{\text {particle }}-\rho_{\text {fluid }}\right) / \mu^{2}$ if the cubed length scale $L_{A r}^{3}=V L^{2} / A$, yielding $C_{\mathrm{D}}^{\mathcal{F}}(R e)=A r / R e^{2}$, as previously highlighted by others (e.g. Karamanev, 1996). However, we will proceed with the original form of Eqn 6 to keep key variables such as $L$ explicit.

If $C_{\mathrm{D}}$ were known for a particular morphology, we could simply substitute values corresponding to the original test in seawater into Eqn 6 and solve for $R e=R e^{\mathrm{O}}$ and thus $U^{\mathrm{O}}$ via Eqn 1, immediately solving the problem of unknown settling speed. Unfortunately, the complex shapes of foraminifera (Table 1) coupled with the implicit dependence of $C_{\mathrm{D}}$ on $R e$ means that both variables are generally unknown, and thus far we have only one constraining relationship between $C_{\mathrm{D}}$ and $R e$. More information is required to determine where along this constraint curve the operating $C_{\mathrm{D}}^{\mathrm{O}}$ and $R e^{\mathrm{O}}$ are located. This information can come from experiments in which the sinking speed of scaled-up model particles of various sizes (i.e. scale factors $S$ ) in a viscous fluid is measured directly, allowing us to calculate $R e$ via Eqn 1 and then $C_{\mathrm{D}}^{\mathcal{F}}(R e)$ via Eqn 6 for the models, with appropriate values substituted for each experiment. For clarity, we can rewrite Eqn 6 for a model in terms of $S$ and the original test parameters $\left(L^{\mathrm{O}}, A^{\mathrm{O}}, V^{\mathrm{O}}\right)$ :

$$
C_{\mathrm{D}}^{\mathcal{F}}(R e)=\frac{2\left(\rho_{\text {particle }}-\rho_{\text {fluid }}\right) \rho_{\text {fluid }}(V) \boldsymbol{g}\left(S L^{\mathrm{O}}\right)^{2}}{\left(S^{2} A^{\mathrm{O}}\right) R e^{2} \mu^{2}},
$$

where we use the fact that for a model, $L=S L^{\mathrm{O}}$ and $A=S^{2} A^{\mathrm{O}}$. While one would also expect $V=S^{3} V^{\mathrm{O}}$ for $3 \mathrm{D}$ printed models, limitations of our 3D printer led to variation in $V$ that we overcame using a more general empirical relationship between $S$ and $V$ based on mass measurements - see '3D printer limitations', below. Eqn 7 represents a constraining relationship between $C_{\mathrm{D}}$ and $R e$ for the sinking particle, which we use to collect $\left(R e, C_{\mathrm{D}}\right)$ experimental data points at several $S$. Once sufficient data are collected, we can construct a new, empirical relationship (e.g. a cubic spline fit; indicated by a superscript E) between $C_{\mathrm{D}}$ and $R e$ for a particular particle shape, which we term $C_{\mathrm{D}}^{\mathrm{E}}(R e)$. Finally, we can solve for the operating $R e^{\mathrm{O}}, C_{\mathrm{D}}^{\mathrm{O}}$, and $U^{\mathrm{O}}$ by finding the intersection point between the $C_{\mathrm{D}}^{\mathcal{F}}(R e)$ constraint curve specific to life-size particles sinking in seawater (i.e. Eqn 7 with $S=1$ and $\rho_{\text {particle }}^{\mathrm{O}}, \rho_{\text {fluid }}^{\mathrm{O}}, \mu^{\mathrm{O}}$ ) and our empirical $C_{\mathrm{D}}^{\mathrm{E}}(R e)$ spline curve valid for a particular particle shape moving steadily through any fluid. MATLAB code can be downloaded from https://github.com/matthewwalkerbio/Dynamicscaling.

\section{Study species}

To construct an empirical $C_{\mathrm{D}}^{\mathrm{E}}(R e)$ curve for a particular test morphology, we started with 3D scans of individual specimens from 30 different species (Table 1). The majority of the species were selected from the University of Tohoku museum's database, eForam Stock (http://webdb2.museum.tohoku.ac.jp/e-foram/), with a micro-computed tomography $(\mu \mathrm{CT})$ scan resolution between 2.5 and 3.6 pixels $\mu \mathrm{m}^{-1}$, and were exported as 3D triangular mesh (STL format) files. Specimens of an additional three species were scanned using synchrotron radiationbased micro-computed tomography (SR $\mu \mathrm{CT})$. Imaging was performed at the Imaging Beamline P05 (IBL) (Greving et al., 2014; Haibel et al., 2010; Wilde et al., 2016) operated by the Helmholtz-ZentrumGeesthacht at the storage ring PETRA III (Deutsches Elektronen Synchrotron-DESY, Hamburg, Germany). Specimens were imaged at a photon energy of $14 \mathrm{keV}$ and with a sample to detector distance of $17 \mathrm{~mm}$. For each tomographic scan, 900 projections at equal intervals between 0 and $\pi$ were recorded. Tomographic reconstruction was done via a classical filtered back projection using the RECLBL library (Huesman et al., 1977). For processing, raw projections were binned 2 times resulting in an effective pixel size of the reconstructed volume of $1.44 \mu \mathrm{m}$. These scans were segmented and rendered using SPIERS (Sutton et al., 2012), and again exported in STL format and are available from MorphoSource (https://www.morphosource.org/Detail/ ProjectDetail/Show/project_id/1167). Meshes of all foraminifera were manually checked in Meshlab (Callieri et al., 2012) for integrity.

For species where more than one scan was available, the scan that contained the best-preserved specimen was chosen. By only including one specimen per species, this approach neglects phenotypic plasticity which is demonstrated in planktonic foraminifera (e.g. Lohmann, 1983; Morard et al., 2013), but was chosen because of limitations of $\mu \mathrm{CT}$ scan availability and time constraints on the project.

\section{D printing and model preparation}

The 3D scans allowed us to easily fabricate scaled-up (scale factor $S$ ) physical models of each specimen using a FormLabs Form1+ (Formlabs, Somerville, MA, USA) 3D printer, using FormLabs Clear Resin Version 2 with a layer thickness of $50 \mu \mathrm{m}$ (see Fig. 2D-I for examples) and $x-y$ resolution of $200 \mu \mathrm{m}$. Models were washed and flushed with isopropanol to remove excess resin following Formlabs' guide and allowed to air dry. Support material was removed (Fig. 2I), and the models lightly sanded with 400 grit Wet ' $n$ ' Dry paper, followed by a final isopropanol wash to remove any remaining residue. Once dry, models were filled with mineral oil in preparation for sinking. Clear resin was chosen to allow each model to be checked for bubbles (which would increase the buoyancy of the model). Any bubbles were removed using a 30-gauge needle and syringe.

Following convention, when defining the area $A_{\text {particle }}$ used in the definition of $C_{\mathrm{D}}$ (Eqn 3), we measured the projected area of the sinking foraminifera. Referring to high-resolution images of the sinking model (Fig. S2D), a digital model of the foraminifera was manually aligned to measure the projected area in a plane perpendicular to the sinking direction (Fig. S2D). We used the same procedure to measure the maximum length parallel to the flow $(L)$ for the calculation of Re (Fig. S2D). These choices facilitated objective comparisons of $C_{\mathrm{D}}$ across morphologically diverse species, to be detailed in a future study.

\section{D printer limitations}

Whilst in principle, the volume of a printed model should simply scale according to $V=S^{3} V^{\mathrm{O}}$, because of inherent limitations of the 3D printer as well as difficulty in removing excess resin from small models, we found that this expectation was usually not satisfied, and weighing the models showed that $M / \rho_{\text {particle }}>S^{3} V^{O}$ where $M$ is particle mass (Fig. S2C). Therefore, we estimated $V$ of each model by weighing models on an Entris $224-1 \mathrm{~S}$ mass balance $( \pm 0.001 \mathrm{~g})$ and assuming $\rho_{\text {particle }}$ was $1121.43 \pm 13.73 \mathrm{~kg} \mathrm{~m}^{-3}$, based on the average mass of five $1 \mathrm{~cm}^{3}$ cubes of printed resin. Furthermore, whenever a predicted value for $V$ at a given scale factor $S$ was needed, i.e. in Eqn 7 (see 'Remaining iterations' under 'Iterative approach', below), we based this on cubic spline interpolation of our $V(S)$ data for existing models when sufficient data were available, with extrapolation based on cubic scaling of $V(S)$ if required (see Fig. S2C):

$$
V^{\text {predicted }}(S)= \begin{cases}H(S), & N \geq 3 \\ S^{3} V^{\mathrm{O}}, & N<3 \text { or } S=1,\end{cases}
$$

where $N$ is the number of existing volume measurements (i.e. the 


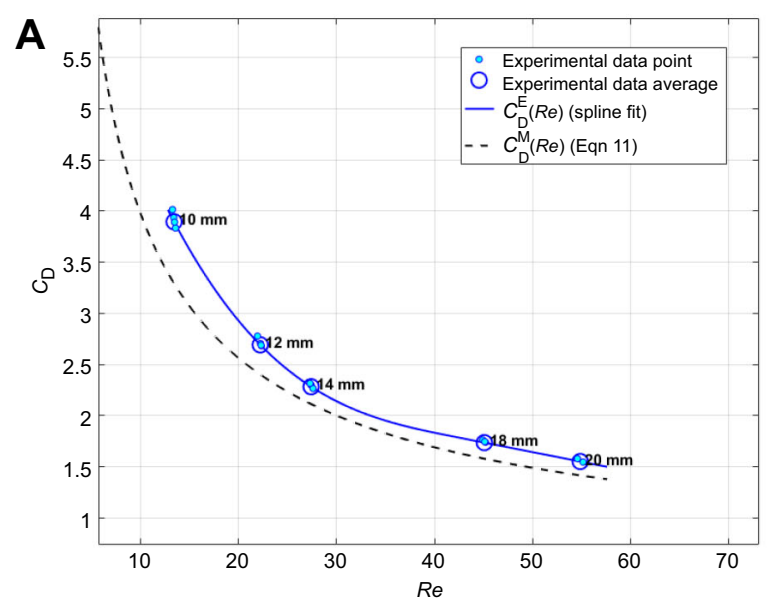

B

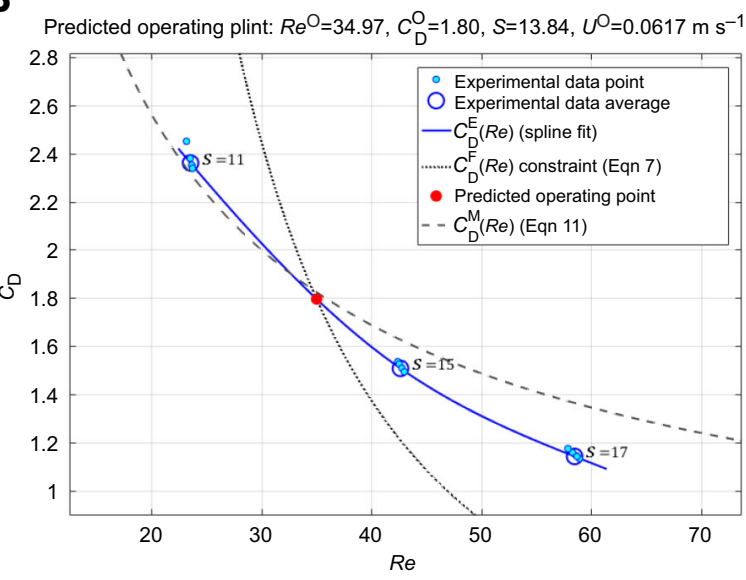

C
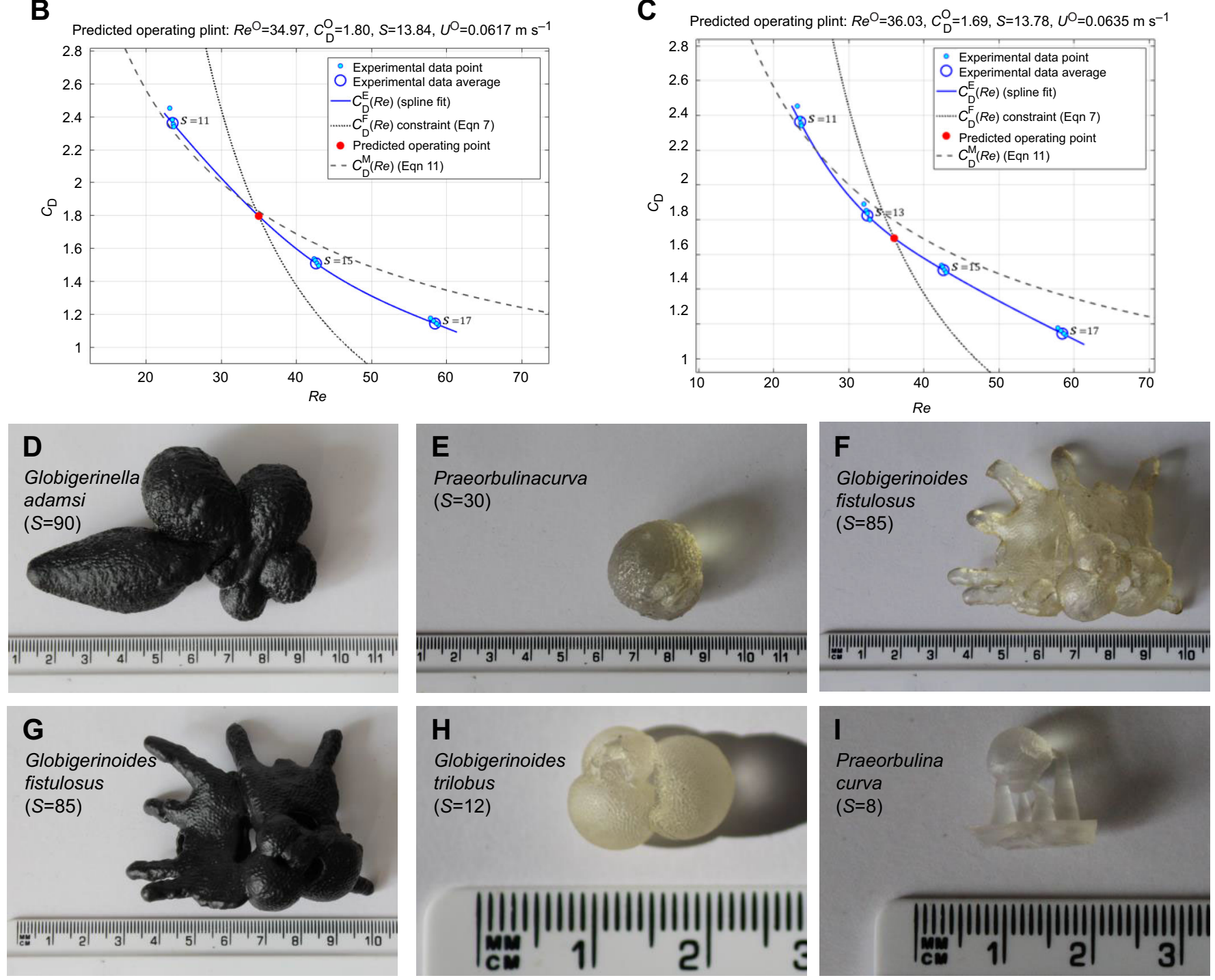

Fig. 2. Application of the method. (A) Comparison of our empirically generated $C_{D}^{E}(R e)$ curve for $3 \mathrm{D}$ printed spheres versus the theoretical $C_{D}^{\mathrm{M}}(R e)$ curve (Morrison, 2010). Goodness of fit of $C_{\mathrm{D}}^{\mathrm{E}}(R e)$ to $C_{\mathrm{D}}^{\mathrm{M}}(R e)$ is $R^{2}=0.857$. Sphere diameter is indicated for each model. (B,C) An example of our iterative solution process for Catapsydrax dissimilis showing best estimates of operating values (including the required model scale $S$ to achieve similitude) based on experimental data from $3(B)$ versus $4(C)$ models. For reference, the theoretical $C_{D}^{M}(R e)$ curve (Morrison, 2010) for a sphere is also shown. In $B$, $S$ corresponding to the operating point is estimated as 13.84 . After an additional model was sunk at $S=13(C)$, slightly more accurate estimates of the operating $S, R e^{\circ}$ and $C_{D}^{O}$ were obtained. When scaling the model for 3D printing, only 1 decimal place was used rather than the 2 shown. (D-I) Models of foraminifera 3D printed in clear and black resin. Models were used for public engagement but demonstrate the fidelity of the printer compared with the scan data shown Table 1. For definitions, see List of symbols and abbreviations. 
current iteration number) and $H$ represents the cubic spline fit of $V$ versus $S$. Note that because we always directly measured $V$ by weighing after printing each model, and it is not necessary to achieve the exact $R e$ and $C_{\mathrm{D}}$ of the operating point $\left(R e^{\mathrm{O}}\right.$ and $\left.C_{\mathrm{D}}^{\mathrm{O}}\right)$ in the experiments (see 'Remaining iterations' under 'Iterative approach', below), the empirical spline-based volume prediction was not strictly required for our method to succeed. It merely aids in improving the rate of convergence of our iterative approach by reducing the difference between our anticipated and actual $R e, C_{\mathrm{D}}$ for each experiment.

\section{Settling tank}

The models were released in a cylindrical acrylic tank $(0.9 \mathrm{~m}$ in diameter and $1.2 \mathrm{~m}$ in height) of mineral oil ('Carnation' white mineral oil, Tennants Distribution Limited, Cheetham, Manchester, UK; $\left.\rho=830 \mathrm{~kg} \mathrm{~m}^{-3}, \mu=0.022 \mathrm{~Pa} \mathrm{~S}\right)$ filled to a depth of $1.18 \mathrm{~m}$ (approximately 750 1). The tank was fitted with a custom-designed net and net retrieval system (Fig. S2A) to allow easy retrieval of the models after their descent, allowing each model to be sunk 5 times. Integrated into the net retrieval system was the release mechanism, which was held centrally over the tank, with the grasping parts submerged below the oil level. This ensured that each model was released in a controlled and repeatable fashion.

\section{Particle imaging}

To minimize reflections, the tank was surrounded by a black fabric tent-like structure. This also served as a dark background to facilitate visualization of the model during descent. The tank was illuminated with a single 800 lumen LED spotlight placed beneath it and, as the Formlab Clear Resin is UV-fluorescent, two $20 \mathrm{~W}$ 'Blacklight' UV fluorescent tubes were placed above the tank.

The sinking models were recorded using two Logitech C920 HD webcams (Logitech, Lausanne, Switzerland), placed at 90 deg to each other (Fig. S2A) and recording at 960 pixels $\times 720$ pixels and $\sim 30$ frames $\mathrm{s}^{-1}$, allowing monitoring of the position and orientation of the particle in 3D as it fell. As these consumer-grade webcams use a variable frame-rate system, a custom-written MATLAB script was used to initiate camera recording, recording both frames and frame time stamps. Videos were recorded for 500 frames $(\sim 17 \mathrm{~s})$. Sinking velocity was calculated over a central $0.8 \mathrm{~m}$ depth range, ensuring the model was at terminal velocity (see 'Time to terminal velocity', below) whilst also avoiding end effects which could slow the model as it reached the bottom of the tank. Based on observations of suspended dust, there was no discernible convection in the tank during any trials that might potentially affect sinking velocity. The curved walls of the tank introduced distortion, which was removed using the MATLAB toolbox 'Camera Calibrator' (McAndrew, 2004). Pixel size was 1.06 pixels $\mathrm{mm}^{-1}$ with a mean reprojection error of 0.5 pixels; therefore, distance measurements (for calculating sinking velocity) were accurate to within $0.5 \mathrm{~mm}(0.06 \%$ of the traversed depth).

\section{Velocity calculation}

Models were tracked in distortion-corrected frames using a modified version of Trackbac (Guadayol et al., 2017; https://zenodo.org/ record/45559\#.W6z6c2j0nIU). The per-frame centroid coordinates obtained were then paired with the time stamp values recorded to calculate average settling velocity components in 2D for each camera (below, $U_{x}$ is horizontal speed from camera one, $U_{y}$ is horizontal speed from camera two, and $U_{z, 1}$ and $U_{z, 2}$ are the vertical speeds corresponding to the two cameras). A resultant velocity magnitude was then calculated for each camera, and these two values were averaged to yield a single estimate for $U$ per experiment:

$$
U=\frac{1}{2}\left(\sqrt{U_{x}^{2}+U_{y}^{2}+U_{z, 1}^{2}}+\sqrt{U_{x}^{2}+U_{y}^{2}+U_{z, 2}^{2}}\right) .
$$

Each model was sunk 5 times and a mean $U$ was calculated from these replicates. Replicates beyond a threshold of $\pm 5 \%$ of the median sinking velocity were discarded from this average. Each model was dropped one additional time and photographed using a Canon 1200D DSLR camera (Tokyo, Japan) mounted on a tripod close to the tank, to obtain high-resolution (18 megapixels) images which were used to determine model orientation (and thus $L$ and $A$ ) during settling (Fig. S2D).

\section{Wall effects}

At low $R e$, the effects of artificial walls in an experimental (or computational) system can be non-intuitively large and lead to substantial errors if not accounted for (Vogel, 1994). Acting as an additional source of drag, the walls several tens of particle diameters away can slow down a sinking particle and increase its apparent drag coefficient. We designed our experiments to minimize wall effects by using a $0.8 \mathrm{~m}$ diameter tank (Fig. S2A) and model diameters of the order of $1 \mathrm{~cm}$. To reduce potential errors further, we applied the method of Fayon and Happel (1960; summarized in Clift et al., 1978) to convert between the apparent drag coefficient when walls are present $\left(C_{\mathrm{D}}^{\text {wall }}\right)$ and the desired drag coefficient in an unbounded domain $\left(C_{\mathrm{D}}^{\infty}\right)$ :

$$
C_{\mathrm{D}}^{\infty} \approx C_{\mathrm{D}}^{\mathrm{walls}}-\frac{24}{\operatorname{Re}}(K(\lambda)-1),
$$

where

$$
K(\lambda)=\frac{1-0.75857 \cdot \lambda^{5}}{1-2.1050 \lambda+2.0865 \lambda^{3}-1.7068 \lambda^{5}+0.72603 \lambda^{6}} .
$$

Here, $\lambda=d / D$ where $d$ is the diameter of the sinking particle and $D$ is the tank diameter; we take $d=L$. While Eqn 10 is not exact, it substantially reduces the error otherwise incurred if one were to neglect wall effects entirely. Note that Eqn 10 is only valid up to about $R e=50$, beyond which different corrections can be used (Clift et al., 1978).

We applied this correction by taking any experimentally determined $C_{\mathrm{D}}$ to equal $C_{\mathrm{D}}^{\text {walls }}$, and using $C_{\mathrm{D}}^{\infty}$ estimated according to Eqn 10 for subsequent calculations as detailed below. In our experiments, $\lambda$ ranged from 0.0027 to 0.0173 , yielding $K$ between 1.0057 and 1.0377. Wall effects were therefore quite small, with $C_{\mathrm{D}}^{\infty} / C_{\mathrm{D}}^{\text {walls }}$ ranging from 0.993 to 0.994 .

\section{Iterative approach \\ First iteration}

To construct an empirical cubic spline $C_{\mathrm{D}}^{\mathrm{E}}(R e)$ needed to solve for $U^{\mathrm{O}}$, at least three experimental data points (corresponding to three scale factors) are needed. These first three $S$ were chosen by using an existing empirical $C_{\mathrm{D}}(R e)$ relationship for a sphere, valid for $0<R e<10^{6}$ (fig. 8.13, page 625 of Morrison, 2013), indicated by 
superscript M:

$$
\begin{aligned}
C_{\mathrm{D}}^{\mathrm{M}}(\operatorname{Re})= & \frac{24}{\operatorname{Re}}+\frac{2.6(\operatorname{Re} / 5.0)}{1+(\operatorname{Re} / 5.0)^{1.52}} \\
& +\frac{0.411(\operatorname{Re} / 263,000)^{-7.94}}{1+(\operatorname{Re} / 263,000)^{-8.00}}+\left(\frac{R e^{0.80}}{461,000}\right) .
\end{aligned}
$$

While morphologically complex particles such as foraminifera tests (Table 1) are not expected to behave like ideal spheres, Eqn 11 should be sufficient to provide initial guesses, after which we iterate to find the solution. We note that if the particle shapes of interest were all most similar to some other well-studied geometry (e.g. cylinders, discs, etc.), using a known $C_{\mathrm{D}}(\operatorname{Re})$ relationship for that shape could provide better initial guesses and faster convergence.

Substituting Eqn 11 into Eqn 7 (with $S=1, V=V^{\mathrm{O}}$, and $\rho_{\text {particle }}^{\mathrm{O}}$, $\rho_{\text {fluid }}^{\mathrm{O}}, \mu^{\mathrm{O}}$ substituted) and moving all terms to one side, we can numerically solve (MATLAB's fzero function) for our first estimate of the operating $R e^{\mathrm{O}}$. Substituting this $R e$ back into Eqn 7 or Eqn 11 yields an estimate of the operating $C_{\mathrm{D}}^{\mathrm{O}}$. We aimed to reproduce this $R e$ and $C_{\mathrm{D}}$ in the first experiment, except that we accounted for wall effects by distinguishing between $C_{\mathrm{D}}^{\infty}$ and $C_{\mathrm{D}}^{\text {walls }}$ expected to occur in the tank. Hence, we could again substitute this Re into Eqn 7 but now with $\rho_{\text {particle }}$ corresponding to the resin model and $\rho_{\text {fluid }}$ and $\mu$ corresponding to mineral oil, and combine this expression with Eqn 10 , assuming our estimated $C_{\mathrm{D}}=C_{\mathrm{D}}^{\infty}, C_{\mathrm{D}}^{\mathcal{F}}=C_{\mathrm{D}}^{\text {walls }}$ and $\lambda=S L^{\mathrm{O}}$ $D$. The resulting expression can be solved numerically for the first scale factor, termed $S_{1}$. Two more scale factors $\left(S_{2}\right.$ and $\left.S_{3}\right)$, one smaller and one larger than $S_{1}$, were chosen to span expected $R e$ values for foraminifera from published literature (e.g. Fok-Pun and Komar, 1983; Takahashi and Be, 1984; Caromel et al., 2014) as well as $R e^{\mathrm{O}}$ for other species which had reached convergence. This procedure was intended to bound the correct $S$ value that reproduces the operating $R e^{\mathrm{O}}$ and $C_{\mathrm{D}}^{\mathrm{O}}$ of the settling particle. The three models were printed, their actual volumes $V$ measured via weighing, and their settling velocities $U$ experimentally measured as detailed in the preceding sections.

An empirical cubic spline curve $C_{\mathrm{D}}^{\mathrm{E}}(R e)$ can now be fitted (http://www.mathworks.co.uk/matlabcentral/fileexchange/24443slm-shape-language-modeling) to these three initial $\left(R e, C_{\mathrm{D}}\right)$ data points, constrained to be monotonically decreasing and concaveup within the limits of the data to match expectations for drag on objects at low to moderate $R e$. Three optimally spaced spline knots were used as this yielded excellent fits to the data as the number of data points increased. These details of the spline as well as its order (i.e. cubic versus linear) are somewhat arbitrary but we ensured that our results were sufficiently converged as to be insensitive to them (see 'Remaining iterations', below).

The operating point $\left(R e^{\mathrm{O}}, C_{\mathrm{D}}^{\mathrm{O}}\right)$ corresponding to the particle settling in the natural environment can be visually represented as the intersection point of the $C_{\mathrm{D}}^{\mathcal{F}}(R e)$ curve defined by Eqn 7 (with $S=1$ and $\left.\rho_{\text {particle }}^{\mathrm{O}}, \rho_{\text {fluid }}^{\mathrm{O}}, \mu^{\mathrm{O}}\right)$ and the empirical $C_{\mathrm{D}}^{\mathrm{E}}(R e)$ relationship based on our experimental data. Algebraically, the operating point is the solution to $C_{\mathrm{D}}^{\mathcal{F}}(R e)=C_{\mathrm{D}}^{\mathrm{E}}(R e)$. We solved for $R e^{\mathrm{O}}$ numerically using a root finding algorithm (MATLAB's fzero function) on the objective function $C_{\mathrm{D}}^{\mathcal{F}}(R e)-C_{\mathrm{D}}^{\mathrm{E}}(R e)=0$ and then obtained $C_{\mathrm{D}}^{\mathrm{O}}$ by substituting $R e^{\mathrm{O}}$ into Eqn 7. Finally, $U^{\mathrm{O}}$ was easily determined from the definition of $R e^{\mathrm{O}}$ (Eqn 1 with $U^{\mathrm{O}}, \mathrm{L} U^{\mathrm{O}}$ and $\rho_{\text {fluid }}^{\mathrm{O}}$ substituted).

Because our first three empirical data points and fitted spline $C_{\mathrm{D}}^{\mathrm{E}}$ corresponded to guessed model scale factors $S$, our initial operating point prediction $\left(R e^{\mathrm{O}}, C_{\mathrm{D}}^{\mathrm{O}}\right)$ often was not located near any of these initial points or sometimes even within the bounds of these data (in which case linear extrapolation of $C_{\mathrm{D}}^{\mathrm{E}}$ was used to estimate the operating point). Therefore, to ensure the accuracy of our predicted $U^{\mathrm{O}}$, we continued iterating with additional experiments.

\section{Remaining iterations}

The model scale factor for the $N$ th experiment was chosen by combining Eqns 7, 8 and 10 with $R e=R e^{\mathrm{O}}$ and $C_{\mathrm{D}}^{\text {walls }}=C_{\mathrm{D}}^{\mathrm{O}}$ (from the previous iteration), $C_{\mathrm{D}}^{\mathcal{F}}=C_{\mathrm{D}}^{\infty}$ and $V=V^{\text {predicted }}$, and numerically solving for $S$. A model close to this new scale was printed and sunk, its settling velocity $U$ recorded and $R e$ and $C_{\mathrm{D}}$ computed, and a more accurate spline $C_{\mathrm{D}}^{\mathrm{E}}$ constructed by including this new data point. The calculation of $\left(R e^{\mathrm{O}}, C_{\mathrm{D}}^{\mathrm{O}}\right)$ detailed in the previous section was then repeated, yielding a more accurate operating point. Overall, the aim was to tightly bound the predicted operating point with experimental data to maximize confidence in the fitted spline in this region.

The iterative process (visualized as a flowchart, Fig. 1B, with a specific example of convergence given in Fig. 2B,C) was repeated until: (1) the predicted operating point was not extrapolated beyond our existing data, (2) the variation in calculated $U^{\mathrm{O}}$ between the fitting of a linear spline and cubic spline was no greater than $5 \%$, and (3) the variation between the predicted $R e^{\mathrm{O}}$ and the closest experimentally measured $R e$ was less than $15 \%$.

In many cases, the difference between results based on four versus three data points was very small (Fig. 2B,C), indicating rapid convergence and the possibility of streamlining the method further in the future. Through this method, we calculated the sinking velocity of 30 species of planktonic foraminifera (Table 1).

\section{Method validation}

Our basic methodology was first validated by $3 \mathrm{D}$ printing a series of spherical models (10-20 mm in diameter) for which the theoretical $C_{\mathrm{D}}(R e)$ relationship is already well known. In order to achieve low density (and thus low sinking velocity and low $R e$ ), these spheres were hollow and filled with oil via two small holes (of diameter $0.8 \%$ of the sphere diameter). Our empirically generated $C_{\mathrm{D}}^{\mathrm{E}}(R e)$ curve compares favourably with the theoretical $C_{\mathrm{D}}^{\mathrm{M}}(R e)$ curve (Morrison, 2010) $\left(R^{2}=0.875\right.$, Fig. 2A), with the distance between the curves approximately constant above $R e \approx 25$. While the error grows larger at lower $R e$, we expected most foraminifera species to operate at $R e \approx 18-55$ based on previous work (Berger and Piper, 1972; Fok-Pun and Komar, 1983; Takahashi and Be, 1984; Caromel et al., 2014).

To quantify errors in our approach even more directly, we then considered hypothetical hollow spherical particles with the same material density $\left(\rho_{\text {particle }}^{\mathrm{O}}\right)$ as foraminifera tests and a range of sizes $\left(L^{\mathrm{O}}=750-1150 \mu \mathrm{m}\right.$, similar to the species we studied) settling in seawater. This size range corresponds to $R e=12-27$, the area where our $C_{\mathrm{D}}^{\mathrm{E}}(R e)$ curve is most divergent from $C_{\mathrm{D}}^{\mathrm{M}}(R e)$. We compared predictions of the operating $U^{\mathrm{O}}$ based on our empirical $C_{\mathrm{D}}^{\mathrm{E}}(R e)$ curve versus the theoretical $C_{\mathrm{D}}^{\mathrm{M}}(R e)$ curve for spheres as outlined above, substituting Eqn 11 for $C_{\mathrm{D}}^{\mathrm{E}}(R e)$ in the latter case. Maximum relative error in predicted $U^{\mathrm{O}}$ was $11.5 \%$ at $R e=16$ (corresponding to a sphere $860 \mu \mathrm{m}$ in diameter) while the minimum difference was $6.5 \%$ at $R e=27$ (corresponding to a sphere of $1150 \mu \mathrm{m}$ in diameter, Fig. 2A). This level of error is much smaller than the variation in $U^{\mathrm{O}}$ we predicted across the 30 foraminifera species we investigated (Table 1).

\section{Time to terminal velocity}

This study was concerned with predicting steady sinking speed, but in our experiments, each model foraminifera took a finite amount of 
time to accelerate from rest at the point of release to its terminal sinking velocity. As this transient portion of the sinking trajectory could introduce errors into our analysis, it is important to determine whether it affected any of our recorded data.

During the transient acceleration phase, Eqn 2 does not hold. Instead, we can revert to the more general form of Newton's second law:

$$
\Sigma F=F_{\text {drag }}+F_{\text {buoyancy }}-F_{\text {weight }}=-M a=-M \frac{\mathrm{d} U}{\mathrm{~d} t},
$$

where $M=V \rho_{\text {particle }}$ is particle mass, and the acceleration $a$ can be equated to the time derivative of instantaneous velocity $\mathrm{d} U / \mathrm{d} t$. A negative sign appears on the right-hand side of the equation so that we can define the downward movement as positive for convenience. We can then substitute expressions for each force as before:

$$
\frac{1}{2} C_{\mathrm{D}}(\Psi, R e) \rho_{\text {fluid }} U^{2} A+V \rho_{\text {fluid }} \boldsymbol{g}-V \rho_{\text {particle }} \boldsymbol{g}=-M \frac{\mathrm{d} U}{\mathrm{~d} t} .
$$

While thus far we have not assumed anything about the particle shape, to proceed further we require knowledge of $C_{\mathrm{D}}(\Psi, R e)$ from vanishingly small $R e$ (when the particle is at rest) up to the terminal velocity. Hence, we will assume a spherical particle as an approximation to the model foraminifera, so that Morrison's empirical equation (Eqn 11) can then be substituted for $C_{\mathrm{D}}(\Psi, R e)$ :

$$
\begin{aligned}
& -\left\{1 / 2\left[\frac{24}{\operatorname{Re}}+\frac{2.6(\operatorname{Re} / 5.0)}{1+(\operatorname{Re} / 5.0)^{1.52}}+\frac{0.411(\operatorname{Re} / 263,000)^{-7.94}}{1+(\operatorname{Re} / 263,000)^{-8.00}}\right.\right. \\
& \left.\left.+\left(\frac{\operatorname{Re} e^{0.80}}{461,000}\right)\right] \rho_{\text {fluid }} U^{2} A+V \rho_{\text {fluid }} \boldsymbol{g}-V \rho_{\text {particle }} \boldsymbol{g}\right\} / M=\frac{\mathrm{d} U}{\mathrm{~d} t} .
\end{aligned}
$$

Here, we have isolated $\mathrm{d} U / \mathrm{d} t$ on the right-hand side of the equation. If the definition of $R e=\left(L U \rho_{\text {fluid }}\right) / \mu$ is inserted into Eqn 14 (not shown for brevity), one obtains an ordinary differential equation (ODE) for the unsteady velocity $U(t)$. The depth of the sphere $Z(t)$ can then be obtained by solving a second much simpler ODE:

$$
U=\frac{\mathrm{d} Z}{\mathrm{~d} t} .
$$

Both ODEs are easily solved numerically by, for example, MATLAB's ode45 function, subject to the initial conditions $U(t=0)=0$ and $Z(t=0)=0$.

It is well known that as $R e$ approaches zero in the limit of inertia-less Stokes flow, unsteadiness can only occur as a result of time-varying boundary conditions. Thus, a microorganism that stops actively swimming will almost instantly come to a stop, and a heavy micro-particle released from rest will almost instantly begin sinking at its terminal velocity (Purcell, 1977). As Re increases and inertia becomes increasingly important, the transient period of acceleration becomes longer. Therefore, a reasonable worst case to examine here is the foraminifera model that sank at the highest $R e$.

We found Globorotalia (Truncorotalia) truncatulinoides to operate at $R e=42$ (Table 1) but here we conservatively chose the largest scale model used to generate its $C_{\mathrm{D}}^{\mathrm{E}}(R e)$ spline for which $S=16$ and $R e=90$. Inserting this model's length $L$, area $A$, and measured volume $V$ into Eqn 14, we obtain solutions for the timevarying speed and depth of a sphere approximating this model's geometry (Fig. S2B). The depth corresponding to where speed equals $99.9 \%$ of the terminal velocity is approximately $4.6 \mathrm{~cm}$, which is much smaller than the $19 \mathrm{~cm}$ between where the models were released and the edge of the cameras' field of view for data collection. Hence, the transient acceleration of each model foraminifera should have had no effect on our data or results. Most of our models should have reached terminal velocity even sooner as they sank at lower Re, e.g. within $2.2 \mathrm{~cm}$ for Catapsydrax dissimilis operating at $R e=36$ (Table 1).

\section{RESULTS AND DISCUSSION}

Here, we present a novel method of determining settling speed by leveraging dynamically scaled models falling under gravity rather than being towed at a controlled speed. Applying our method to foraminifera-inspired spherical particles (Fig. 2A), we predict settling speeds within $11.5 \%$ of theoretical expectations (Fig. S2E). In Fig. 2B,C we present an example of convergence of our method to the operating $R e^{\mathrm{O}}, C_{\mathrm{D}}^{\mathrm{O}}$ and $U^{\mathrm{O}}$ of a typical foraminifera species. There was little variation in the number of iterations required to reach convergence (mean 4, range 3-6; see Table 1), despite the morphological complexity of some species (e.g. Globigerinoidesella fistulosa). We suspect the higher end of this range was due to these species having forms that were particularly challenging to clean residual resin from, or to the incomplete removal of air bubbles once submerged in oil.

Our predicted sinking speeds of foraminifera fall within aggregated existing data for 14 species (Fig. S1; Fok-Pun and Komar, 1983; Takahashi and Be, 1984; Caromel et al., 2014) and compare well with known speeds for other particles of comparable size and density (e.g. faecal pellets: table 3 of Iversen and Ploug, 2010; phytoplankton: fig. 1 of Smayda, 1971). However, it should be noted that our predicted speeds are higher than published values for five out of the seven foraminifera species for which direct comparisons are possible (Fig. S1). This could be due to our ability to observe enlarged models of sinking foraminifera more accurately compared with actual specimens, and the lack of control for wall effects in previous work, which would tend to underestimate sinking speeds. There could also be considerable natural variation, which our single specimen per species (excluding Sphaeroidinella dehiscens) does not capture.

Sedimentation of microscale plankton has been measured both in situ (e.g. Waniek et al., 2000) and in the laboratory (e.g. Smayda, 1971; Miklasz and Denny, 2010). By settling dense suspensions of microorganisms, these studies provided a population sinking rate (Bienfang, 1981) which could be 2-3 times lower than the settling velocity of an isolated particle in the typically dilute ocean (Miklasz and Denny, 2010). Other studies have, as in the present study, used enlarged models of microscale plankton to facilitate observations. Padisák et al. (2003) used handmade models of plankton to examine drag, but there was no attempt to accurately match Re. Holland (2010) used mechanical pencil leads as models of sinking diatom chains, keeping $R e<1$ in an improvement over Padisák et al. (2003). However, neither study calculated sinking velocity for real organisms. Our dynamic scaling approach ensured that we accurately recreate the fluid flows around settling organisms - a requirement for the correct prediction of sinking speed. We also improved on previous methodologies by effectively eliminating wall effects, basing our models on $\mu \mathrm{CT}$ scans, and using inexpensive cameras to observe natural sinking orientation.

By design, our dynamic scaling approach yields an interpolated $C_{\mathrm{D}}(R e)$ curve that describes the flow dynamics (and thus sinking speeds) that would occur if various fluid and/or particle parameters were varied, offering a degree of flexibility not seen in other studies. For example, phytoplankton blooms can increase both the density and 
viscosity of water due to exudates (Jenkinson et al., 2015), while increasing global temperatures have the opposite effect. The density and viscosity of seawater also naturally vary with latitude. Understanding how these variations affect sinking rates can offer insights into the evolutionary pressures on plankton. Our approach also allows us to isolate the effects of shape on sinking, even across species of widely varying size, density, etc., by comparing $C_{\mathrm{D}}$ of different species all hypothetically sinking at the same $R e$; a manuscript focused on such biological questions relating to foraminifera is currently in preparation. Differential settling speeds of foraminfera also have implications for nutrient cycling, paleoclimate reconstruction (Kucera, 2007) and the marine calcite budget (Schiebel, 2002).

Our method can easily be modified to study sedimenting particles operating at any $R e$, providing the system's $R e$ range can be experimentally replicated. Other sinking marine particles include diatoms ( $R e \approx 10^{-2}$ to 1 ; Botte et al., 2013) and radiolaria $(\operatorname{Re} \approx 10-200$; Takahashi and Honjo, 1983), for which one could use digital models as we have in conjunction with a suitably viscous fluid (high viscosity silicone oil; see Table S1) to enable sufficiently large models to be produced $(25 \mathrm{~cm}$; see Table $\mathrm{S} 1)$. The method can also be applied to terrestrial systems such as settling spores $(R e \approx 50 ;$ e.g. Gómez-Noguez et al., 2016; Noblin et al., 2009) and dispersing seeds (Re $\approx 10^{3}$; Osuki et al., 2017; Azuma and Yasuda, 1989), again by using 3D printed models based on (often existing) $\mu \mathrm{CT}$ data.

Whilst our method pertains to settling in a quiescent fluid, one could conduct similar experiments using a flume to calculate threshold resuspension velocity (i.e. the horizontal flow speed required to lift a particle off the substrate), important in the study of wind erosion and particle transport and deposition (Bloesch, 1995; Bagnold, 1971). Similarly, studying particles suspended in shear flow could be achieved using a treadmill-like device (e.g. Durham et al., 2009) or a Taylor-Couette apparatus (e.g. KarpBoss and Jumars, 1998). While additional dimensionless groups beyond $R e$ and $C_{\mathrm{D}}$ would need to be matched to achieve similitude in these systems, we hope that our study provides a starting point for the experimental study of these and other more complex problems.

\section{Acknowledgements}

Our thanks go to Michael Kucera for supplying samples of planktonic foraminifera. We thank Alex Blanke for preparing the samples and taking them to Hamburg. We also thank the rest of the Physical Ecology Lab (School of Life Sciences, University of Lincoln: Òscar Guadayol i Roig, Fouad El Baidouri, Mariona Segura, Jackson Sage and Sei Suzuki-Teller) for their support and help during the project. Our thanks go to Gregory Sutton and David Smith for their comments on a draft of the manuscript and we also thank Mark Denny, Matthew A. Reidenbach and one anonymous reviewer for their comments.

\section{Competing interests}

The authors declare no competing or financial interests.

\section{Author contributions}

Conceptualization: M.W., S.H.; Methodology: M.W., J.U.H., F.W., S.H., R.S.; Software: M.W., R.S.; Validation: M.W., R.S.; Formal analysis: M.W., R.S.; Investigation: M.W.; Resources: M.W., T.H., S.H.; Data curation: M.W., R.S.; Writing - original draft: M.W., R.S.; Writing - review \& editing: M.W., S.H., R.S.; Visualization: M.W., R.S.; Supervision: S.H., R.S.; Project administration: M.W., S.H.; Funding acquisition: S.H.

\section{Funding}

All research was funded by Leverhulme Trust, grant/award number RL-2012- 022, awarded to S.H. High-resolution scanning was funded by a grant from the Deutsches Elektronen-Synchrotron (DESY: I-20140099 EC) awarded to Prof. Michael Fagan and Dr Alex Blanke. Open access funding provided by University of Lincoln. Deposited in PMC for immediate release.

\section{Data availability}

MATLAB code can be downloaded from GitHub: https://github.com/ matthewwalkerbio/Dynamic-scaling. Scans are available from MorphoSource: https://www.morphosource.org/Detail/ProjectDetail/Show/project_id/1167.

\section{Supplementary information}

Supplementary information available online at

https://jeb.biologists.org/lookup/doi/10.1242/jeb.230961.supplemental

\section{References}

Ali, A., Thiem, Ø. and Berntsen, J. (2011). Numerical modelling of organic waste dispersion from fjord located fish farms. Ocean Dyn. 61, 977-989. doi:10.1007/ s10236-011-0393-8

Azuma, A. and Yasuda, K. (1989). Flight performance of rotary seeds. J. Theor Biol. 138, 23-53. doi:10.1016/S0022-5193(89)80176-6

Bagnold, R. A. (1971). The Physics of Blown Sand and Desert Dunes. Dover Earth Science. Dordrecht: Springer Netherlands. Available from: http://link.springer. com/10.1007/978-94-009-5682-7.

Batchelor, G. K. (2000). An Introduction to Fluid Dynamics. Cambridge University Press. Available from: https://www.cambridge.org/core/product/identifier/ 9780511800955/type/book.

Berger, W. H. and Piper, D. J. W. W. (1972). Planktonic foraminifera: differential settling, dissolution, and redeposition. Limnol. Oceanogr. 17, 275-287. doi:10. 4319/lo.1972.17.2.0275

Bienfang, P. K. (1981). SETCOL - a technologically simple and reliable method for measuring phytoplankton sinking rates. Can. J. Fish. Aquat. Sci. 38, 1289-1294. doi:10.1139/f81-173

Bloesch, J. (1995). Mechanisms, measurement and importance of sediment resuspension in lakes. Mar. Freshw. Res. 46, 295. doi:10.1071/MF9950295

Booth, J. D. (1983). Studies on twelve common bivalve larvae, with notes on bivalve spawning seasons in New Zealand. N. Z. J. Mar. Freshw. Res. 17, 231-265. doi:10.1080/00288330.1983.9516001

Botte, V., Ribera D'Alcalà, M. and Montresor, M. (2013). Hydrodynamic interactions at low Reynolds number: an overlooked mechanism favouring diatom encounters. J. Plankton Res. 35, 914-918. doi:10.1093/plankt/fbt033

Callieri, M., Ranzuglia, G., Dellepiane, M., Cignoni, P. and Scopigno, R. (2012) Meshlab as a complete open tool for the integration of photos and colour with highresolution 3D geometry data. Comput. Appl. Q. Methods Archaeol. 406-416.

Caromel, A. G. M., Schmidt, D. N., Phillips, J. C. and Rayfield, E. J. (2014). Hydrodynamic constraints on the evolution and ecology of planktic foraminifera. Mar. Micropaleontol. 106, 69-78. doi:10.1016/j.marmicro.2014.01.002

Clift, R., Grace, J. R. and Weber, M. E. (1978). Bubbles, Drops and Particles. New York: Academic Press.

De La Rocha, C. L. and Passow, U. (2007). Factors influencing the sinking of POC and the efficiency of the biological carbon pump. Deep Sea Res. II Top. Stud. Oceanogr. 54, 639-658. doi:10.1016/j.dsr2.2007.01.004

Durham, W. M., Kessler, J. O. and Stocker, R. (2009). Disruption of vertical motility by shear triggers formation of thin phytoplankton layers. Science 323, 1067-1070. doi:10.1126/science.1167334

Fayon, A. M. and Happel, J. (1960). Effect of a cylindrical boundary on a fixed rigid sphere in a moving viscous fluid. AIChE J. 6, 55-58. doi:10.1002/aic.690060111

Fok-Pun, L. and Komar, P. D. (1983). Settling velocities of planktonic foraminifera; density variations and shape effects. J. Foraminiferal Res. 13, 60-68. doi:10.2113/ gsjfr.13.1.60

Gómez-Noguez, F., Pérez-García, B., Mehltreter, K., Orozco-Segovia, A. and Rosas-Pérez, I. (2016). Spore mass and morphometry of some fern species. Flora Morphol. Distrib. Funct. Ecol. Plants 223, 99-105. doi:10.1016/j.flora.2016. 05.003

Greving, I., Wilde, F., Ogurreck, M., Herzen, J., Hammel, J. U., Hipp, A., Friedrich, F., Lottermoser, L., Dose, T., Burmester, H. et al. (2014). P05 imaging beamline at PETRA III: first results. In Developments in X-Ray Tomography IX (ed. S. R. Stock), p. 921200. San Diego, CA: SPIE. Available from: https://doi.org/10.1117/12.2061768

Guadayol, Ò., Thornton, K. L., Humphries, S. (2017). Cell morphology governs directional control in swimming bacteria. Sci. Rep. 7, 2061. doi:10.1038/s41598017-01565-y

Gupta, B. K. S. (ed.) (2002). Modern Foraminifera. Kluwer Academic Publishers.

Haibel, A., Ogurreck, M., Beckmann, F., Dose, T., Wilde, F., Herzen, J., Müller, M., Schreyer, A., Nazmov, V., Simon, M. et al. (2010). Micro- and nanotomography at the GKSS Imaging Beamline at PETRA III. Proc. SPIE 7804 Developments in X-Ray Tomography VII, 78040B (20 September 2010). https:// doi.org/10.1117/12.860852

Holland, D. P. (2010). Sinking rates of phytoplankton filaments orientated at different angles: theory and physical model. J. Plankton Res. 32, 1327-1336. doi:10.1093/plankt/fbq044

Huesman, R. H., Gullberg, W. L., Greenberg, W. L. and Budinger, T. F. (1977) RECLBL users manual: Donner algorithms for reconstruction tomography. Available from: https://escholarship.org/uc/item/1mz679x3\#main. 
Iversen, M. H. and Ploug, H. (2010). Ballast minerals and the sinking carbon flux in the ocean: carbon-specific respiration rates and sinking velocity of marine snow aggregates. Biogeosciences 7, 2613-2624. doi:10.5194/bg-7-2613-2010

Jenkinson, I. R., Sun, X. X. and Seuront, L. (2015). Horizons: Thalassorheology, organic matter and plankton: towards a more viscous approach in plankton ecology. J. Plankton Res. 37, 1100-1109. doi:10.1093/plankt/fbv071

Jones, R., Ricardo, G. F. and Negri, A. P. (2015). Effects of sediments on the reproductive cycle of corals. Mar. Pollut. Bull. 100, 13-33. doi:10.1016/j.marpolbul. 2015.08.021

Jonkers, L. and Kučera, M. (2015). Global analysis of seasonality in the shell flux of extant planktonic Foraminifera. Biogeosciences 12, 2207-2226. doi:10.5194/bg12-2207-2015

Karamanev, D. G. (1996). Equations for calculation of the terminal velocity and drag coefficient of solid spheres and gas bubbles. Chem. Eng. Commun. 147, 75-84. doi:10.1080/00986449608936496

Karp-Boss, L. and Jumars, P. A. (1998). Motion of diatom chains in steady shear flow. Limnol. Oceanogr. 43, 1767-1773. doi:10.4319/lo.1998.43.8.1767

Kim, M. J., Bird, J. C., Van Parys, A. J., Breuer, K. S. and Powers, T. R. (2003) A macroscopic scale model of bacterial flagellar bundling. Proc. Natl. Acad. Sci. USA 100, 15481-15485. doi:10.1073/pnas.2633596100

Koehl, M. A. R. (1995). Fluid flow through hair-bearing appendages: feeding smelling, and swimming at low and intermediate Reynolds number. In Biological Fluid Dynamics (ed. C. P. Ellington and T. J. Pedley), pp. 157-182. Cambridge: The Company of Biologists Limited.

Koehl, M. A. R. (2003). Physical modelling in biomechanics. Philos. Trans. R. Soc Lond. Ser. B Biol. Sci. 358, 1589-1596. doi:10.1098/rstb.2003.1350

Kucera, M. (2007). Chapter six planktonic foraminifera as tracers of past oceanic environments. In Developments in Marine Geology, pp. 213-262. London: Elsevier.

Lohmann, G. P. (1983). Eigenshape analysis of microfossils: a general morphometric procedure for describing changes in shape. J.Int. Assoc. Math Geol. 15, 659-672. doi:10.1007/BF01033230

McAndrew, A. (2004). An Introduction to Digital Image Processing with Matlab Notes for SCM2511 Image Processing 1 Semester 1, 2004. https://www. academia.edu/36758058/An_Introduction_to_Digital_Image_Processing_with_ Matlab_Notes_for_SCM2511_Image_Processing_1)

Miklasz, K. A. and Denny, M. W. (2010). Diatom sinkings speeds: improved predictions and insight from a modified Stokes' law. Limnol. Oceanogr. 55, 2513-2525. doi:10.4319/lo.2010.55.6.2513

Morard, R., Quillévéré, F., Escarguel, G., de Garidel-Thoron, T., de Vargas, C. and Kucera, M. (2013). Ecological modeling of the temperature dependence of cryptic species of planktonic Foraminifera in the Southern Hemisphere. Palaeogeogr Palaeoclimatol. Palaeoecol. 391, 13-33. doi:10.1016/j.palaeo.2013.05.011

Morrison, F. A. (2013). An Introduction to Fluid Mechanics. Cambridge: Cambridge University Press.

Morrison, F. A. (2010). Data Correlation for Drag Coefficient for Sphere, Vol. 6 pp. 1-2. Houghton, Ml: Michigan Technology University. Available from: http:/ www.chem.mtu.edu/ fmorriso/DataCorrelationForSphereDrag2013.pdf.

Munson, B. R., Young, D. F. and Okiishi, T. H. (1994). Fundamentals of Fluid Mechanics. 2nd edn. New York: John Wiley and Sons, Inc.

Noblin, X., Yang, S. and Dumais, J. (2009). Surface tension propulsion of funga spores. J. Exp. Biol. 212, 2835-2843. doi:10.1242/jeb.029975

Oskui, S. M., Bhakta, H. C., Diamante, G., Liu, H., Schlenk, D. and Grover, W. H. (2017). Measuring the mass, volume, and density of microgram-sized objects in fluid. PLOS ONE 12, e0174068. doi:10.1371/journal.pone.0174068

Padisák, J., Soróczki-Pintér, É. and Rezner, Z. (2003). Sinking properties of some phytoplankton shapes and the relation of form resistance to morphological diversity of plankton - an experimental study. Hydrobiologia 500, 243-257. doi:10. 1023/A:1024613001147

Passow, U. and Carlson, C. A. (2012). The biological pump in a high $\mathrm{CO}_{2}$ world. Mar. Ecol. Prog. Ser. 470, 249-271. doi:10.3354/meps09985
Purcell, E. M. (1977). Life at low Reynolds number. Am. J. Phys. 45, 3-11. doi:10 1119/1.10903

Reidenbach, M. A., George, N. and Koehl, M. A. R. (2008). Antennule morphology and flicking kinematics facilitate odor sampling by the spiny lobster, Panulirus argus. J. Exp. Biol. 211, 2849-2858. doi:10.1242/jeb.016394

Schiebel, R. (2002). Planktic foraminiferal sedimentation and the marine calcite budget. Global Biogeochem. Cycles 16, 3-1-3-21. doi:10.1029/2001GB001459 Schiebel, R. and Hemleben, C. (2005). Modern planktic foraminifera. Paläontol. Z. 79, 135-148. doi:10.1007/BF03021758

Smayda, T. J. (1971). Normal and accelerated sinking of phytoplankton in the sea Mar. Geology 11, 105-122. doi:10.1016/0025-3227(71)90070-3

Sowa, Y. and Berry, R. M. (2008). Bacterial flagellar motor. Q. Rev. Biophys. 41, 103-132. doi:10.1017/S0033583508004691

Stacey, M. T., Mead, K. S. and Koehl, M. A. R. (2002). Molecule capture by olfactory antennules: Mantis shrimp. J. Math. Biol. 44, 1-30. doi:10.1007/ s002850100111

Stadler, A. T., Vihar, B., Günther, M., Huemer, M., Riedl, M., Shamiyeh, S., Mayrhofer, B., Böhme, W. and Baumgartner, W. (2016). Adaptation to life in aeolian sand: how the sandfish lizard, Scincus scincus, prevents sand particles from entering its lungs. J. Exp. Biol. 219, 3597-3604. doi:10.1242/jeb.138107

Sutton, M. D., Garwood, R. J., Siveter, D. J. and Siveter, D. J. (2012) SPIERS and VAXML; A software toolkit for tomographic visualisation and a format for virtual specimen interchange. Paleontol. Electron. 15, 1-15. doi:10. $26879 / 289$

Takahashi, K. and Be, A. W. H. (1984). Planktonic foraminifera: factors controlling sinking speeds. Deep Sea Res. A. Oceanogr. Res. Papers 31, 1477-1500. doi:10. 1016/0198-0149(84)90083-9

Takahashi, K. and Honjo, S. (1983). Radiolarian skeletons: size, weight, sinking speed, and residence time in tropical pelagic oceans. Deep Sea Res. A Oceanogr. Res. Papers 30, 543-568. doi:10.1016/0198-0149(83)90088-2

Van Sebille, E., Scussolini, P., Durgadoo, J. V., Peeters, F. J. C. C., Biastoch, A., Weijer, W., Turney, C., Paris, C. B. and Zahn, R. (2015). Ocean currents generate large footprints in marine palaeoclimate proxies. Nat. Commun. 6, 6521 doi:10.1038/ncomms7521

Vogel, S. (1987). Flow-assisted mantle cavity refilling in jetting squid. Biol. Bull. 172 61-68. doi:10.2307/1541606

Vogel, S. (1994). Life in Moving Fluids. 2ndn. Princeton, NJ: Princeton University Press.

Vogel, S. and LaBarbera, M. (1978). Simple flow tanks for research and teaching Bioscience 28, 638-643. doi:10.2307/1307394

Vogel, S., Ellington, C. P. and Kilgore, D. L. (1973). Wind-induced ventilation of the burrow of the prairie-dog,Cynomys ludovicianus. J. Comp. Physiol. 85, 1-14 doi:10.1007/BF00694136

Waldrop, L. D., Reidenbach, M. A. and Koehl, M. A. R. (2015). Flexibility of crab chemosensory sensilla enables flicking antennules to sniff. Biol. Bull. 229, 185-198. doi:10.1086/BBLv229n2p185

Walsby, A. E. and Holland, D. P. (2006). Sinking velocities of phytoplankton measured on a stable density gradient by laser scanning. J. R. Soc. Interface. 3 429-439. doi:10.1098/rsif.2005.0106

Waniek, J., Koeve, W. and Prien, R. D. (2000). Trajectories of sinking particles and the catchment areas above sediment traps in the northeast Atlantic. J. Mar. Res. 58, 983-1006. doi:10.1357/002224000763485773

Wilde, F., Ogurreck, M., Greving, I., Hammel, J. U., Beckmann, F., Hipp, A Lottermoser, L., Khokhriakov, I., Lytaev, P., Dose, T. et al. (2016). Micro-CT at the imaging beamline P05 at PETRA III. AIP Conference Proceedings. 1741 (July)

Willson, M. F., Rice, B. L. and Westoby, M. (1990). Seed dispersal spectra: a comparison of temperate plant communities. J. Veg. Sci. 1, 547-562. doi:10.2307/ 3235789

Zohuri, B. (2015). Dimensional Analysis and Self-Similarity Methods for Engineers and Scientists. Cham: Springer International Publishing. Available from: http://link. springer.com/10.1007/978-3-319-13476-5 